\title{
Trip generation: Introduction to the special section
}

\author{
Susan Handy ${ }^{a}$ \\ University of California, Davis
}

When a developer proposes a new project, cities in the United States invariably ask the questions: How many new vehicle trips will the project generate? And how much worse will traffic get as a result? The answers to these questions trigger responses of great consequence. Most often, predictions of increases in vehicle trips - and thus, traffic congestion — lead cities to plan for increases in intersection and roadway capacity to handle the increased traffic, often paid for by sizable impact fees imposed on developers. More recently, cities have been asking for modifications to the project itself to reduce the number of vehicle trips generated, for example, through demand-management strategies. Either way, the trip generation estimation and the resulting traffic impact assessment may shape public support for or resistance to the project. Accurate trip generation estimates are thus crucial.

In the United States, trip generation estimation relies on the process outlined in the ninth edition of the Institute of Transportation Engineer's Trip Generation Manual. This manual, one of the icons of transportation planning, reports rates derived from field-collected data for different land-use categories (e.g., single-family residential or office or retail) as an average number of trips per unit of land use (e.g., square footage), or for some categories as a linear or non-linear function. Use of the ITE manual is nearly universal, but it also has widely known limitations. The key issue is the data on which the ITE trip generation rates are based: data have mostly been collected at suburban sites, the number of sites for some land-use categories is very small, and some data are decades old. These issues produce a serious concern: Are ITE rates in fact applicable to the proposed project?

The trip generation rates in the ITE Trip Generation Manual are especially a concern for development projects that are less auto-oriented than the suburban sites at which the trip-generation data have been collected. In one study, traffic counts at residential transit-oriented developments were, on average, 44 percent lower than suggested by ITE rates (Arrington and Cervero 2008). Another study found that ITE rates overestimated trips by 48 percent for mixed-use sites and 94 percent for infill sites (Shafizadeh et al. 2012). Overestimating vehicle trips is a problem because it could lead to costly efforts to mitigate traffic that will never materialize or needlessly fuel a NIMBY ("not in my backyard") response to infill projects that would actually help to reduce auto dependence. Many jurisdictions allow for adjustments to trip generation estimates for projects where transit, walking, or bicycling are likely, and indeed the ITE manual recommends such adjustments, though it provides limited guidance on how to make them. The need for methods to more accurately estimate trip generation for such projects-increasingly encouraged by cities in the United States - is clear.

Currans and Clifton (2015) offer such a method in the article "Using household travel surveys

${ }^{a}$ slhandy@ucdavis.edu

Copyright 2015 Susan L. Handy

http://dx.doi.org/10.5198/jtlu.2015.822

ISSN: 1938-7849 | Licensed under the Creative Commons Attribution - NonCommercial License 3.0.

The Journal of Transport and Land Use is the official journal of the World Society for Transport and Land Use (WSTLUR) and is published and sponsored by the University of Minnesota Center for Transportation Studies. 
to adjust ITE trip generation rates." Using data from household travel surveys from Oregon, Washington, and Maryland in conjunction with nationally available data on the built environment, the study develops models for estimating mode split and vehicle occupancy for a development project based on surrounding land-use characteristics. Analysts can derive an estimate of vehicle trips for the site by applying the mode split and vehicle occupancy estimates from these models to an estimate of person trips for the project. The method for estimating person trips is a bit mind-twisting: Estimates of vehicle trips based on the ITE rates are assumed to be roughly equivalent to person trips, given the suburban location of most of the sites from which the rates are derived. Currans and Clifton's tests of adjustments for 195 establishments show that this method produces more accurate trip generation estimates than the ITE rates on their own.

In the article "Adjusting ITE's Trip Generation Handbook for urban context," Clifton, Currans, and Muhs (2015) take a different approach to developing a method for adjusting vehicle trip rates from the ITE manual to account for the built environment surrounding a proposed project. This study uses data collected at 78 establishments in Portland, Oregon, focusing on high-turnover restaurants, convenience markets, and drinking places, located in a variety of settings, from suburban to city center sites. Because of the strong correlations between built environment characteristics (e.g., activity density, length of bicycle facilities, intersection density), the study estimates separate models for each of nine different characteristics. Analysts can use these models to calculate an adjustment to the ITE rate to reflect the built environment characteristics of that project.

Schneider, Shafizadeh, and Handy (2015) take a similar approach in the article "Method to adjust Institute of Transportation Engineers vehicle trip-generation estimates in smart-growth areas." This study uses data from 50 sites in California that qualify as "smart growth" by meeting specified criteria for population and employment density, land-use mix, transit access, and bicycle and pedestrian facilities. These sites fall into the land-use categories of mid- to high-density residential, office, coffee/donut, multiuse, and retail. Because the models are based on data from only smart-growth sites, the method includes screening criteria to determine if the method applies for a specific project. To deal with the strong correlations between built environment characteristics, the study developed a composite "smartgrowth factor," incorporating multiple characteristics, that is used to estimate the adjustment factor. It then incorporated the models into a spreadsheet tool for easy application of the method.

Just how inaccurate are trip generation estimates based on the ITE rates overall? Millard-Ball (2015) takes a creative approach to answering this question at a national scale in the article "Phantom trips: Overestimating the traffic impacts of new development." For the United States, Millard-Ball compares estimates of vehicle trips for selected purposes from the National Household Travel Survey (NHTS) to estimates of vehicle trips for certain land uses based on national data on building square footage combined with ITE trip generation rates. From both cross-sectional and longitudinal analysis, Millard-Ball concludes that ITE trip rates overestimate vehicle trips by as much as 55 percent. The reasons for the discrepancy are not entirely clear, but the article points to a fundamental problem: The ITE method assumes, for the most part, that new development generates new trips rather than drawing existing trips from old destinations to the new one. In other words, trips that are new to the immediate area of the new development may not be new to the overall system. This analysis points to the importance of scale when analyzing traffic impacts and to the need for methods that better distinguish between shifts in trip destinations and truly new trips.

Another limitation of the ITE method is its focus on peak-hour travel and thus passenger travel. An explosion in deliveries associated with online shopping is contributing to a growing recognition of the challenges of goods movement within urban environments, including impacts on parking and traffic as well as the environment and overall quality of life. These issues highlight the need for a better under- 
standing of the generation of freight trips outside of ports, container terminals, and other industrial sites. Jaller, Wang, and Holguin-Veras (2015) contribute to this understanding in the article "Large urban freight traffic generators: Opportunities for city logistics initiatives." The study focuses on methods for identifying large urban freight generators, referred to as LTGs, including large building or landmarks and large establishments. Freight models previously developed by the authors can be applied to the identified LTGs. Such estimates are important for identifying effective planning and policy strategies, such as off-hours deliveries and centralized receiving stations.

This set of articles conveys an important message: We need better tools for estimating trip generation, and to develop better tools we need more data collection. Careful testing shows that the methods presented in the first three of these articles generally yield more accurate trip generation estimates than the ITE rates on their own, especially in urban contexts. But as the studies all emphasize, these new methods are just a starting point, an improvement on existing methods but with significant limitations of their own. These limitations stem, for the most part, from data limitations: the small number of urban sites for which trip-generation data are available relative to the large number of land-use categories, built environment characteristics, and other factors that might influence trip generation. Unfortunately, collecting trip data at urban sites is difficult and expensive; the automated vehicle trip counters used at suburban sites are useless for sites where residents or customers park off-site or arrive by transit, walking, or bicycling. Ideally, data-collection methods would capture all modes of passenger travel as well as freight trips. With such data in hand, researchers would be able to develop models that both produce more accurate estimates of vehicle trips and generate trip estimates for other passenger modes and for freight. Such estimates would help to ensure adequate provision for these modes and not just for cars.

These articles also point to the need for change in professional practice. While the widespread use of the ITE Trip Generation Manual provides consistency and bolsters credibility, it also impedes the adoption of more than marginal improvements to existing methods. The efforts described in this issue to develop methods that improve the accuracy of trip-generation estimates and make the estimates sensitive to the local context address an important need. These efforts and others in the trip generation realm complement other current movements in the transportation planning field, including the shift to multimodal measures of level-of-service and, in California, the shift away from level-of-service measures altogether to a focus on vehicle miles traveled in the environmental review process. But such changes do not happen overnight. New trip-generation methods are likely to face resistance from practitioners as well as policymakers, the public, and the courts, at least until enough examples of their application have accumulated that they become accepted practice. Recent revisions to the process guidelines in the ITE manual are a good start, but the field still has far to go.

\section{References}

Arrington, G. B., and R. Cervero. 2008. Effects of TOD on Housing, Parking, and Travel, Transit Cooperative Research Program Report 128. Washington, DC: Transportation Research Board.

Clifton, K., K. Currans, and C. Muhs. 2015. Adjusting ITE's Trip Generation Handbook for urban context. The Journal of Transport and Land Use 8(1): 1-25. Retrieved March 27, 2015, from http:// jtlu.org.

Currans, K., and K. Clifton. 2015. Using household travel surveys to adjust ITE trip generation rates. The Journal of Transport and Land Use 8(1): 1-35. Retrieved March 27, 2015, from http://jtlu.org.

Institute of Transportation Engineers. 2012. Trip Generation Manual. Ninth Edition. Washington, DC: ITE. 
Jaller, M., X. Wang, and J. Holguín-Veras. 2015. Large urban freight traffic generators: Opportunities for city logistics initiatives. The Journal of Transport and Land Use 8(1): 1-17. Retrieved March 27, 2015, from http://jtlu.org.

Millard-Bell, A. 2015. Phantom trips: Overestimating the traffic impacts of new development. The Journal of Transport and Land Use 8(1): 1-19. Retrieved March 27, 2015, from http://jtlu.org.

Schneider, R., K. Shafizadeh, and S. Handy. 2015. Method to adjust Institute of Transportation Engineers vehicle trip-generation estimates in smart-growth areas. The Journal of Transport and Land Use, 8(1): 1-15. Retrieved March 27, 2015, from http://jtlu.org.

Shavizadeh, K., R. Lee, D. Niemeier, T. Parker, and S. Handy. 2012. Evaluation of the operation and accuracy of available smart growth trip generation methodologies for use in California. Transportation Research Record 2307: 120-131. 